\title{
DOADOR RENAL - UM ESTUDO QUALITATIVO EM UMA ANÁLISE PSICOLÓGICA
}

\author{
Kidney donor - a qualitative research on the analytic psychology
}

\author{
Marina de Castro Nascimento
}

\begin{abstract}
RESUMO
O transplante renal é vivido como uma situação de crise não apenas pelo receptor, mas também pelo doador. A decisão de doar um órgão vai além da escolha individual, sendo perpassada pela dinâmica familiar e social. É uma intervenção não apenas no corpo (procedimento cirúrgico), mas também na psique (significado emocional) e no convívio social (manejo de expectativas do meio, afastamento temporário do trabalho e da vida social). Objetivos: Verificar a compreensão e a percepção do doador frente ao transplante, pesquisar as motivações e emoções do doador com relação ao transplante renal e compreender o lugar do doador na dinâmica familiar. Método: Pesquisa qualitativa com seis doadores em pré-transplante renal, por meio de entrevista semidirigida e testes projetivos (Desenho da Família e Desenho Temático). Resultados: Os doadores indicaram como sua principal motivação o desejo de ajudar o outro e proporcionar uma melhor qualidade de vida para o receptor. Fatores sociais como cumprir com o seu papel familiar e desejo de evitar, além do sofrimento do paciente, o seu próprio e de outros familiares, também se mostraram importantes na decisão. Mostraram-se pouco informados sobre o transplante e, ao lado da satisfação em ajudar, emoções como tristeza, medo e insegurança também estão presentes. Conclusão: O presente estudo indica a importância do atendimento psicológico com os doadores como espaço para trabalhar questões emocionais relativas ao transplante, buscando contribuir para o desenvolvimento pessoal do indivíduo.
\end{abstract}

Descritores: Transplante de Rim, Doadores Vivos, Psicologia.

Instituição:

Faculdade de Psicologia da Pontifícia Universidade Católica de São Paulo (PUC-SP), São Paulo - SP - Brasil

\section{Correspondência:}

Marina de Castro Nascimento

Rua Marquês de Praia Grande, nº 540 apt 151 bloco B, Vila Prudente - CEP: 03129-110

São Paulo - SP

Tel: (11) 9109-1533

E-mail: marinacn@uol.com.br

\section{INTRODUÇÃO}

Os rins fazem parte do sistema urinário e suas funções são basicamente, de regulação, controle e filtragem. A Insuficiência Renal Crônica (IRC) é o resultado da perda lenta e progressiva das funções renais ${ }^{1}$. Até que tenha perdido cerca de metade de sua função renal, os pacientes permanecem quase sem sintomas. As queixas dos pacientes com I.R.C. são variadas, como mal estar generalizado e náuseas, e dependem do estágio da doença. ${ }^{1}$

Os tratamentos são hemodiálise, diálise, uso de medicações, dieta alimentar, e, a partir da década de 80, os transplantes renais passaram a ser uma importante opção terapêutica para pacientes portadores de $\mathrm{IRC}^{2}{ }^{2}$ além de ser um recurso favorável à melhor qualidade de vida de pacientes com IRC terminal. ${ }^{3}$

Em 1997, a Legislação Brasileira definiu a política para a prática dos transplantes, com o intuito de garantir acesso amplo e democrático, além de avanços éticos nessa prática. ${ }^{4}$ Já em 1998 foi implementada a Coordenação Nacional do Sistema Nacional de Transplante, cujas responsabilidades, entre outras, são a captação e a distribuição de órgãos. ${ }^{5}$

O transplante é uma técnica cirúrgica que consiste na colocação de um rim saudável no paciente com IRC terminal, podendo ser este de um doador-cadáver ou de um doador-vivo. A opção que oferece melhores resultados com relação à sobrevida do paciente e do enxerto é a de doadores vivos. ${ }^{3}$

A doação de órgãos é uma forma singular de doação. Além da importância biológica da cirurgia como recurso terapêutico, o 
transplante tem um significado emocional para a dupla doadorreceptor e para a família. A doação de órgãos envolve, além dos riscos da cirurgia, sentimentos, expectativas e faz com que tanto o receptor quanto o doador se deparem com a possibilidade da morte.

A presença da doença e suas repercussões exigem mudanças de hábitos na rotina do paciente e de seus familiares, resultando na necessidade de processos adaptativos, podendo assim ser vivida como uma crise familiar. ${ }^{6}$

O transplante pode intensificar essa crise, pois a dinâmica familiar é afetada a partir dessa possibilidade de tratamento que implica em responder: quem será o doador?

A decisão de ser doador engloba, além das expectativas e pressões familiares, questões emocionais, a ambivalência em querer doar e os medos e conflitos desencadeados pela situação. ${ }^{2,7,8}$

Alguns autores ${ }^{6,8,9,10}$ sugerem que as motivações para a doação de órgãos não são sempre conscientes, podendo existir num mesmo indivíduo motivações inconscientes e antagônicas geradoras de conflitos. Tais motivações podem ser conteúdos do inconsciente, pessoal ou coletivo, ou seja, conteúdos que não se tornaram conscientes, por não terem sido integrados pelo Ego, centro regulador da psique. ${ }^{11}$

Cada vivência tem certo número de elementos desconhecidos por nós, pelo fato de não termos acesso a toda a realidade concreta, uma vez que nossa consciência não consegue abranger tudo. ${ }^{11}$

A doença ou as experiências corporais, como o transplante renal, são situações significativas e, sob a óptica da Psicologia Analítica, não podemos pensá-las como algo desvinculado da experiência psíquica, por serem essas experiências as bases formadoras de símbolos estruturantes do Ego. ${ }^{11}$

O Ego faz o elo entre o consciente e o inconsciente, sendo que as duas instâncias têm uma dimensão individual/pessoal, tendo sua origem nas aquisições do indivíduo e conteúdos esquecidos ou reprimidos, e outra coletiva que tem sua origem desconhecida, embora seus elementos não sejam adquiridos e sim próprios do humano: os arquétipos. ${ }^{12}$

A possibilidade do sujeito, no caso o doador, entrar em contato com conteúdos inconscientes e poder integrar na psique vivências como o transplante, é algo de grande valor para o processo de desenvolvimento, ou seja, de individuação.

Uma possibilidade de se trabalhar com a experiência do transplante é através de técnicas projetivas, e, pela análise simbólica, com a amplificação dos conteúdos, isto porque somos seres simbólicos e a maior parte de nós é inconsciente. Jung ${ }^{11}$ indica: "a consciência é como uma superfície ou película cobrindo uma vasta área inconsciente, cuja extensão é desconhecida [...] estamos mergulhados no inconsciente, que contém todas as possibilidades humanas.”

A proposta desta pesquisa foi pensar, sob a óptica da Psicologia Analítica, o significado da doação do rim, tendo como objetivos: verificar a compreensão e a percepção do doador frente ao transplante, pesquisar as motivações e emoções do doador com relação ao transplante renal, e compreender o lugar do doador na dinâmica familiar.

Por fim, a literatura ${ }^{2}$ indica que há ainda poucos estudos sobre a experiência e o significado emocional do transplante para o doador, sendo importantes trabalhos referentes a este tema.

\section{MÉTODO}

Este estudo foi realizado adotando-se como metodologia de pesquisa a abordagem qualitativa, por ser mais congruente com os princípios da Psicologia Analítica, na qual se entende que cada sujeito tem uma história, embora seja possível uma compreensão mais generalizada quando se pensa nos motivos coletivos e sociais para a doação. ${ }^{13}$

O grupo de investigação foi composto por seis doadores, sendo quatro homens e duas mulheres, com o seguinte grau de parentesco: irmãos(4), pai(1) e mãe(1). A idade variou entre 32 e 67 anos. Os critérios de inclusão no grupo foram: ser adulto (entre 21 e 70 anos), ser parente consangüíneo do paciente e estar na etapa final de seleção para ser doador.

As vias de acesso para avaliar as motivações e emoções frente ao transplante foram:

1. entrevista semidirigida ${ }^{14}$ abordando os itens: Informações relativas ao transplante, Motivações, Expectativas e Emoções.

2. técnicas projetivas gráficas: Desenho da Família ("Faça uma família". Caso o sujeito perguntasse que família, a orientação foi: "Qualquer família”) e Desenho Temático ("Desenhe como é, para você, o transplante") ou Imaginação Semidirigida (quando o doador referia dificuldade em realizar o Desenho Temático).

Enquanto a entrevista permite a manifestação mais consciente do sujeito, os desenhos permitem as manifestações de conteúdos menos conscientes ou inconscientes. ${ }^{15}$

As respostas obtidas com a entrevista foram analisadas a partir de 3 campos de investigação e relacionadas com os desenhos e seus respectivos inquéritos. As análises dos Testes Projetivos foram feitas conforme os pressupostos teóricos de seus autores. ${ }^{16,17,18}$

Os encontros foram individuais e tiveram em média duração de uma hora e trinta minutos. Antes do início da coleta, explicou-se o objetivo da pesquisa e cada doador recebeu o Termo de Consentimento Livre e Esclarecido, autorizando o registro e o uso dos dados coletados para fins deste estudo.

\section{RESULTADOS}

Com relação ao gênero dos doadores houve o predomínio de homens (quatro homens para duas mulheres), embora em Livramento ${ }^{2}$ haja indicação de um predomínio de mulheres pela questão da "maternagem". Como o número de participantes desse estudo era quantitativamente pequeno, não foi possível avaliar a relação entre gênero e número de doadores, e, por isso, esse dado não fez parte do foco de interesse da pesquisa.

Os resultados foram organizados a partir de três campos de investigação: cognitivo, afetivo-pessoal e social-familiar.

- Cognitivo: relativo às informações dos doadores acerca da doença do receptor e do transplante, observadas a partir de questões da entrevista (Qual o seu conhecimento sobre a doença (I.R.C) e o tratamento (hemodiálise, diálise peritonial)? O que você sabe sobre transplante?) e do Desenho Temático (Desenhe como é, para você, o transplante).

Os doadores, de modo geral, relatam saber pouco sobre IRC, os tratamentos pelos quais o receptor é submetido e o próprio transplante. Alguns referiram ainda dificuldade em compreender o que lhe era dito. 
Alguns exemplos são: “[...] mesmo que falem, eu não guardo nas idéias as coisas", “[...] conversar com os outros, eles só dão medo na gente... eu vim fazer um exame nas virilha, e todo mundo falando que era duro, que era isso, e aquilo. Eu não achei não" e "Você sabe que está fazendo uma cirurgia, mas você não sabe a gravidade ou se tem gravidade. Eu não sei nenhum tipo de informação de se isso pode me prejudicar depois ou não.” Indicara, via desenho, fragilidade, insegurança e distanciamento frente à situação vivida. Um doador relatou imaginar a situação de transplante como "[..] os médicos quando estão assim (operando), faz a maior farra, a maior festa. Eu sei porque já fiz uma cirurgia" e "O que tiver que ser será".

- Afetivo-pessoal: relativo às motivações e emoções referentes ao transplante observadas a partir de questões da entrevista (Por que decidiu ser doador e como foi o processo de escolha dentro da família? O que você sente em relação ao transplante? O que você tem sentido do processo de seleção (consultas, exames, etc?).

A doação aparece como uma oportunidade para fortalecer laços com o receptor ou com a família, mas também como um momento de preocupações com relação à cirurgia, e pressões por parte da família atual (filhos, esposas).

Com relação às motivações foi possível verificar que a decisão dos doadores, num primeiro momento, não foi espontânea, e sim por exclusão (nenhum outro familiar poderia ser o doador por motivos de saúde ou por motivos pessoais, como medo), por escolha da família (no caso de um sujeito, pelo fato de sua família ter feito uma "reunião" e ele ter sido o escolhido, mesmo não estando nesse dia por ter tido outro compromisso); apenas um sujeito relatou que um outro irmão e a mãe também tinham se prontificado a doar.

Apesar deste momento "arbitrário", os doadores referem querer doar para ajudar o receptor e para que ele tenha melhor qualidade de vida, além de fatores relacionados à postura do receptor, percebida pelo doador como força de vontade, desejo de viver, e sofrimento com o tratamento. Há ainda, como motivação, o lugar que o doador ocupa ou imagina ocupar na dinâmica familiar, como será observado mais adiante.

Assim, cinco dos seis sujeitos submeteram-se ao processo de doação para melhorar a qualidade de vida do receptor e/ou para ajudá-lo, dois dos seis sujeitos resolveram doar para cumprir com o papel familiar e com as expectativas da família e deles próprios com relação à responsabilidade de ser irmão, e apenas um doador indicou como motivação influência religiosa.

Com relação às emoções, indicaram afeto pelo receptor, sentimento de fraternidade, tristeza ao ver o receptor vivenciando o tratamento para IRC, além de insegurança em relação ao transplante.

- Social-familiar: relativo ao lugar do doador na dinâmica da família, observado a partir de questões da entrevista (Qual a constituição familiar? O que você acha da sua relação com o paciente? Por que decidiu ser doador? Como foi o processo de escolha dentro da família?) e do Desenho da Família.

De modo geral, nos Desenhos da Família, em especial quando há a ilustração de pessoas, é possível observar um investimento reduzido, retraimento, fragilidade e falta de apoio.

Dois sujeitos não desenharam suas próprias famílias, e não incluem o receptor e nem eles mesmos; uma doadora representa a família por meio de flores, dois doadores desenham a família que desejam ter no futuro, e apenas um doador desenhou sua família atual (esposa e filhos).

Com relação ao lugar na dinâmica familiar, é possível verificar o lugar em que o doador se coloca (dar a salvação ao receptor, cumprir com o papel familiar) ou lugar em que é colocado pela família (corajoso, saudável). Falaram sobre o receptor como alguém que vivencia dificuldades e sofrimentos, mas que tem força de vontade, não desanima.

Os doadores indicaram, também, insegurança e expectativas sobre as repercussões do transplante em sua vida pessoal e social.

\section{DISCUSSÃO}

$\mathrm{Na}$ pesquisa realizada para este trabalho, todos os doadores indicaram uma postura comprometida durante a coleta.

Com relação ao campo cognitivo, a falta de informação pode ser em decorrência do conflito vivido, de querer saber e de ter medo em saber, além de uma dificuldade de compreensão e elaboração, ou ainda por receberem pouca informação, segundo o discurso trazido por dois doadores entrevistados para esta pesquisa.

Com relação ao campo afetivo-pessoal, foi possível observar, no discurso de alguns doadores, que o transplante atua como um elemento de aproximação com o receptor, sendo aspectos comuns em quatro doadores, sentimento de insegurança, além de afetividade e preocupação com o receptor.

Já com relação ao campo social-familiar, alguns sujeitos indicaram uma sensação de obrigatoriedade em doar, à medida que outros familiares ou o próprio paciente referiam ser ele a única esperança, tornando este processo mais difícil para os doadores. ${ }^{19}$

$\mathrm{Na}$ literatura estudada, ${ }^{6,20}$ aparece a questão do transplante como situação de crise, tanto pessoal quanto familiar, e isso pode ser verificado no discurso dos sujeitos, um afirmando que "toda família já ficou nervosa com a situação", outro relatando a ocorrência de uma reunião familiar para decidir quem seria o doador. Para o doador o transplante é vivenciado como uma crise, pelos sentimentos de fragilidade, luto, e por exigir o afastamento temporário de sua rotina, como pôde ser observado nos Resultados sobre os possíveis impactos que o transplante pode gerar.

Observando as repostas dos sujeitos, a não ser no caso de um deles, foi possível perceber que a religião não tem ou tem pouca influência direta sobre a decisão de doar, diferentemente do indicado em estudos de Simmions (apud LIVRAMENTO²), no qual a religião é um fator intrínseco que exerce grande influência na decisão.

O transplante surge como um recurso importante que a ciência desenvolveu para auxiliar a vida de muitos indivíduos, sendo também umas das possibilidades de se exercer cidadania e ajudar o próximo. É também uma situação onde elementos arquetípicos podem se fazer presentes (por exemplo o do herói, do curador, da grande mãe, etc), além de conteúdos da sombra, e o contato com emoções, desejos, medos, todos elementos importantes para o desenvolvimento do indivíduo, processo de individuação, caso possam ser trabalhados e re-significados.

O doador não tem insuficiência renal e nunca fez hemodiálise, mas compartilha com o receptor a condição de paciente, quando inicia os exames de seleção, os preparativos pré-cirúrgicos e a recuperação no pós-operatório. 
A literatura indica a importância do doador, na primeira entrevista, ser avaliado sobre o grau de motivação e voluntarismo, e ser informado a respeito de todas as avaliações e procedimentos pelos quais irá passar, ${ }^{6}$ e ser submetido a uma avaliação psicológica para receber orientações e suporte. ${ }^{2}$

A avaliação psicológica em pré-transplante é importante, também, para prevenir futuras complicações, à medida que a avaliação possibilita o acesso a informações sobre a história do sujeito. $\mathrm{Na}$ avaliação deve ser garantida a confidencialidade ao sujeito. ${ }^{8}$

A avaliação e a intervenção em saúde mental com os doadores para transplante é conduta necessária para a abordagem adequada das questões emocionais envolvidas, buscando na avaliação identificar, entre outras coisas, o contexto em que se deu a decisão de ser doador, os fatores motivacionais envolvidos, o vínculo anterior e atual com o receptor, a dinâmica familiar, etc. ${ }^{21}$

A avaliação psicológica integra o protocolo de procedimentos nos centros transplantadores, com o intuito de verificar o estado mental do doador, assegurando se o candidato tem capacidade para esta tomada de decisão, e ainda verificar o processo de tomada de decisão e as questões psicossociais envolvidas. ${ }^{19}$ No preparo psicológico há conteúdos importantes a serem trabalhados como a significação que o doador dá ao órgão, o conhecimento real ou fantasioso da situação, as expectativas, etc. ${ }^{22}$

Sendo responsabilidade do psicólogo promover e garantir saúde e qualidade de vida, além de favorecer o desenvolvimento do indivíduo, sua função no Setor de Transplantes é dar espaço, como indica a literatura e os dados apresentados, quer através de trabalho em grupo ou individual, para que o doador possa expressar suas dúvidas, seus medos e suas fantasias, tendo um profissional qualificado do campo "psi” desenvolvendo um trabalho que possibilite reflexões e uma decisão com a maior inteireza e consciência possível.

\section{CONCLUSÃO}

As questões colocadas ao longo do trabalho são relevantes por buscarem compreender a vivência do transplante para o sujeito que assume ser doador. Fazendo um trabalho pré-transplante com instrumentos como entrevista e testes projetivos, através da leitura simbólica, é possível verificar o que essa doação está revelando de modo que a vivência possa ser um instrumento para a ampliação da consciência favorecendo o processo de individuação, à medida que se integram novos conteúdos, emoções e idéias.

O desenvolvimento de um trabalho multiprofissional em uma configuração de grupo psicoeducativo durante o processo de seleção do doador, e acompanhamento psicológico pós-cirúrgico, podem contribuir com este importante processo terapêutico, que é repleto de emoções, muitas vezes ambivalentes, como indica o presente trabalho e a literatura, além de oferecer informações e oportunidade de troca de experiências.

\section{AGRADECIMENTOS}

Agradeço ao Hospital e aos doadores pela oportunidade de realizar este trabalho.

Agradeço à minha Orientadora, Prof ${ }^{a}$ Liliana Liviano Wahba, e aos professores Heloísa D.S.Galan, Sandra Amorim e Arnaldo Motta.

Agradeço também à Prof ${ }^{a}$ Patrícia L. Bellodi por sua tutoria e contribuições.

\section{ABSTRACT}

The kidney transplantation is experienced as a critic situation both by patients and donors. The decision to donate an organ goes beyond a personal choice, as it is influenced by the family and the social dynamic. Is an intervention into the body (surgical procedure), in the psyche (emotional meaning, beliefs) and in social relationships (expectations, pressures, and doubts from the society, added to the temporarily absence from work and social life). Purpose: To check the donor's comprehension on the transplantation, researching the donor's motivations and emotions concerning the kidney transplantation and comprehension of his role inside the family. Method: qualitative research, sample consisted of six individuals, kidney pre-transplantation donors, being the instruments: semi-guided interview and projective tests (Family's Drawing and Thematic's Drawing). Results: Donors indicated their motivation was a wish to help another person, providing him a better quality of life. Factors such as the desire to play his role into the family or wishing to avoid their or others' suffering or from their relatives were important as well. Donors indicated they lack information on the transplantation, and the emotions involved were sadness, preoccupation and insecurity. Conclusion: This work indicates the importance the work from a psychologist with donors as an opportunity to talk about the emotions of a transplant, trying to contribute to the personal development.

Keywords: Kidney Transplantation, Living Donors, Psychology

\section{REFERÊNCIAS BIBLIOGRÁFICAS:}

1. Ianhez LE.Transplante Renal: aspectos clínicos e práticos. São Paulo: Produtos Roche; 2001.

2. Livramento ML. Aspectos psicológicos da doação renal: um estudo exploratório em um hospital universitário [dissertação]. São Paulo: Universidade de São Paulo; 2002.
3. Paula FJ de, Alvarenga EC, Azevedo LS. Evaluación y seleción de receptores y donantes para transplante renal. In: Noronha IL, Manfro RC, Pacheco-Silva A, Casadei D. Manual de transplante renal. Barueri/SP: Manoele; 2007. p. 35-62.

4. Ferraz AS. La legislación y los aspcetos éticos del transplante no Brasil. In:Noronha IL, Manfro RC, Pacheco-Silva A, Casadei D. Manual de transplante renal. Barueri/ SP: Manoele; 2007. p. 421-6. 
5. Mendes FDR, Junior PR de S. El Sistema Nacional de Transplante (SNT): aspectos políticos, econômicos y operacionales del transplante. In: Noronha IL, Manfro RC, Pacheco-Silva A, Casadei D. Manual de transplante renal. Barueri/SP: Manoele; 2007. p. 427- 45.

6. Mello Filho J de. A significação psicológica do implante para o paciente e sua família. Inf psiquiatr.1983 Jan/Março;1(4):3-8.

7. Quintana AM, Muller AC. Da saúde à doença: representações sociais sobre a insuficiência renal crônica e o transplante renal. Psicol argum. 2006 jan/ mar;24(44):73-80.

8. Manfro GG, Blaya CL. Los aspectos psiquiátricos del transplante renal. In: Noronha, IL et al. Manual de transplante renal. In: Noronha IL, Manfro RC, Pacheco-Silva A Casadei D. Manual de transplante renal. Barueri/SP: Manoele; 2007. p. 379-92.

9. Uryn MB. Transplantes renais. In: Mello Filho J (org), editor. Psicossomática hoje. São Paulo:Artes Médicas; 1992. p.279-86.

10. Murray EJ. Motivação e emoção.Rio de Janeiro: Zahar; 1967.

11. Jung CG. Fundamentos de Psicologia Analítica. $4^{\mathrm{a}}$ ed. Petrópolis: Vozes; 1987. p. 1-31, p. 32-64.

12. Byington C. Dimensões simbólicas da personalidade. São Paulo: Ática; 1988.

13. Penna EMD. Um estudo sobre o método de investigação da psique na obra de Carl Gustav Jung [dissertação]. São Paulo: Pontifícia Universidade Católica; 2003.

14. Alves-Mazzotti AJ, Gewndszanajder F. O método das ciências naturais e sociais. São Paulo: Pioneira; 2002.
15. Ocampo MLS e col. O processo psicodiagnóstico e as técnicas projetivas.São Paulo: Martins Fontes; 1990

16. Hammer E. Aplicações clínicas dos desenhos projetivos. São Paulo: Casa do Psicólogo; 1991.

17. Wahba LL. Consciência de si através da vivência corporal [dissertação]. São Paulo: Pontifícia Universidade Católica;1982.

18. Farah RM. Integração psicofísica: o trabalho corporal e a psicologia de Carl Gustav Jung. Soulo DT, editor. São Paulo: Robe Editorial; 1995.

19. Lazzarett CT. Considerações éticas no transplante hepático com doador vivo. Rev SBPH. 2005 Jan/Jun;8(1):p.15-26.

20. Caiuby AVS. Análise do discurso dos doadores renais: uma abordagem psicológica [tese]. São Paulo: Escola Paulista de Medicina; 2001.

21. Rodrigues RTS, Lima MGS, Amorim SF. Transplante renal e hepático, a intervenção psicológica no hospital geral. In: Bruscato WL, Benedetti C, Lopes SR de A. A prática da Psicologia Hospitalar na Santa Casa de São Paulo: novas páginas em uma antiga história. Gunter IB, Chinalli M, editores. São Paulo: Casa do psicólogo; 2004. p.135-53.

22. Garcia MLP, Souza AMA, Holanda TC. Intervenção psicológica em uma unidade de transplante renal de um hospital universitário. Psicol.cienc.prof. 2005 Set;25(3): p. $472-83$. 